\title{
La inobservancia de principios y garantías constitucionales en los casos de reincidencia en materia penal
}

The non-observance of constitutional principles and guarantees in cases of recidivism in criminal matters

\author{
Ivanova María Ramírez-Tenepaguay \\ ivanova.ramirez@ucacue.edu.ec \\ Universidad Católica de Cuenca, Cuenca \\ Ecuador \\ https://orcid.org/0000-0001-7868-0999 \\ Juan Carlos Erazo-Álvarez \\ jcerazo@ucacue.edu.ec \\ Universidad Católica de Cuenca, Cuenca \\ Ecuador \\ https://orcid.org/0000-0001-6480-2270 \\ Cecilia Ivonne Narváez-Zurita \\ inarvaez@ucacue.edu.ec \\ Universidad Católica de Cuenca, Cuenca \\ Ecuador \\ https://orcid.org/0000-0002-7437-9880 \\ Enrique Eugenio Pozo-Cabrera \\ epozo@ucacue.edu.ec \\ Universidad Católica de Cuenca, Cuenca \\ Ecuador \\ https://orcid.org/0000-0003-4980-6403
}

Recibido: 10 de abril de 2020

Revisado: 25 de abril de 2020

Aprobado: 30 de mayo de 2020

Publicado: 17 de junio de 2020 


\title{
RESUMEN
}

Los derechos fundamentales de los ciudadanos se encuentran reconocidos en la Constitución del República del Ecuador (CRE) e Instrumentos Internacionales de Derechos Humanos, siendo de directa e inmediata aplicación, garantizando el derecho a la igualdad de los ciudadanos ante la ley, por lo expuesto se considera que todas las normas infra-constitucionales deberán ser apegadas a la CRE, mismo que en la actualidad estos derechos no están siendo plasmados al momento de la aplicación de la reincidencia penal. Metodológicamente se abordó desde el enfoque mixto. Concluyendo que debería existir la aplicación de los derechos consagrados en la CRE para la persona reincidente en cualquier delito establecido en la norma penal, buscando la efectiva reinserción social como derecho a la igualdad.

Descriptores: Derecho constitucional; procedimiento legal; derecho a la justicia; solución de conflictos. (Palabras tomadas del Tesauro UNESCO).

\begin{abstract}
The fundamental rights of citizens are recognized in the Constitution of the Republic of Ecuador (CRE) and International Human Rights Instruments, being of direct and immediate application, guaranteeing the right to equality of citizens before the law, for what is stated considers that all infra-constitutional norms must be adhered to by CRE, which at the moment these rights are not being reflected at the time of the application of criminal recidivism. Methodologically it was approached from the mixed approach. Concluding that there should be the application of the rights enshrined in the CRE for the recidivist in any crime established in the criminal law, seeking effective social reintegration as a right to equality.
\end{abstract}

Descriptors: Constitutional law; legal procedure; right to justice, conflict resolution. (Words taken from the UNESCO Thesaurus)

\section{INTRODUCCIÓN}

Con la aprobación de la Constitución de la República del Ecuador del 2008 (CRE), Ecuador pasó de ser un "Estado de derecho" (Asamblea Nacional Constituyente, 1998, pág. 1), a convertirse en un Estado garantista de los derechos como se encuentra establecido en la CRE un "Estado constitucional de derechos y justicia social", de este 
modo, los derechos y garantías que se encuentran establecidas en la CRE y "serán de directa e inmediata aplicación", entre los diversos derechos fundamentales de los ciudadanos se puede considerar como principales el derecho a la vida, derechos a la libertad, derecho a la igualdad formal y material, derecho a la no discriminación, derecho a la justicia y al debido proceso (Asamblea Nacional Constituyente, 2008, arts. 1, 11, 66). Sin embargo, no es suficiente que los derechos primordiales se encuentren reconocidos en la CRE, pues siendo un Estado constitucional de derechos, se considera importante que también las normas infra-constitucionales sean adecuadas a lo manifestado en nuestra carta magna, garantizando la dignidad del ser humano o de las comunidades, pueblos y nacionalidades (Asamblea Nacional Constituyente, 2008, art. 84).

Ahora bien, si analizamos la aplicación de la reincidencia en materia penal, considerando que es una norma jurídica infra-constitucional según se encuentras manifestado en el Código Orgánico Integral Penal (COIP) “... la persona que reincide se le impondrá la pena máxima prevista en el tipo penal incrementada un tercio", el Estado y tratadistas, considera que el aumento de la pena es una forma para que las personas que delinquen no vuelvan a reincidir en el mismo delito, imponiendo una pena mayor, con el fin de resguardar la seguridad de la sociedad. (Asamblea Nacional, 2014, art. 57); (Chávez, 2016; Alexy, 2016; Alexy, 2016).

Ante el análisis planteado, es importante determinar si la aplicación de la reincidencia en materia penal se adecúa a los lineamientos constitucionales, considerando que la persona que reincide se le establece la sanción tomando en cuenta el delito actual cometido y su pasado judicial, de tal forma, de manera que su situación jurídica empeora, dentro de esta perspectiva, se puede observar que existe inobservancia a las garantías y principios constitucionales como: principio no bis in ídem principio de proporcionalidad, igualdad formal y material, seguridad jurídica consagrados en la Constitución.

Con el análisis realizado, se considera como problemática ¿cómo mejorar la aplicación de la sanción a las personas que son reincidentes en materia penal sin que se vulnere los principios y garantías constitucionales?, en relación a la problemática expuesta el objetivo es proponer un proyecto de ley para la declaración de inconstitucionalidad 
respecto a las sanciones a las personas que son reincidentes en materia penal.

\section{Referencial teórico}

\section{Garantías y principios constitucionales en el Ecuador}

Las garantías constitucionales son el amparo que establece la CRE, para el efectivo reconocimiento de los derechos ya sean individuales o colectivos, y evitar que los derechos fundamentales se transgredan o se violenten, "las garantías constitucionales tienen por objeto garantizar la regulación de las funciones estatales, la anulación del acto inconstitucional es al que representa la garantía principal y la más eficaz de la Constitución". (Kelsen, p. 34)

Desde el inicio de la historia del derecho, se ha reconocido los derechos de las personas para cumplir un correcto funcionamiento de la sociedad, así mismo; se garantiza los derechos de las personas protegiendo un orden social y estableciendo un territorio, de manera, la CRE siendo un Estado garantista protector de los derechos fundamentales que se encuentran reconocidos en nuestra carta magna, así como también, busca reparar los derechos que han sido vulnerados o violentando (Rojas-Valdivieso, Erazo-Álvarez, Pozo-Cabrera, \& Narváez-Zurita, 2020).

Las garantías constitucionales se encuentran establecidos en el título III de nuestra carta magna, dividiéndose como: garantías normativas, políticas públicas, servicios públicos y participación ciudadana y garantías jurisdiccionales, se interpondrá según lo indica la CRE, cuando exista vulneración a los derechos las cuales pueden ser por una norma, acto administrativo, política pública u omisión por parte de una autoridad administrativa o judicial (Asamblea Nacional Constituyente, 2008).

Según mencionan (Montaña \& Porras, 2011), las garantías normativas tienen como función proteger los derechos fundamentales mediante los principios y reglas, así mismo, se realice el efectivo resarcimiento de los derechos que han sido violentados por parte de los servidores administrativos o judiciales.

Las garantías normativas aseguran los derechos de las personas, “...adecuando de forma material y formal las leyes y las normas jurídicas previstos en la constitución y en 
los tratados Internacionales..." Asegurando que cualquier ley o norma infra-constitucional respete lo manifestado por la Constitución, garantizando la dignidad humana. (Asamblea Nacional Constituyente, 2008, art. 84)

De igual forma, las garantías jurisdiccionales son los mecanismos para proteger los derechos de las personas a través de las acciones como: acción de protección, hábeas corpus, hábeas data, acción de acceso a la información pública, acción por incumplimiento y la acción extraordinaria de protección, según se encuentra señalado en la Constitución del Ecuador, título III, capítulo III, los jueces serán los encargados de conocer las omisiones o violación de derechos y la reparación de los mismo. (Asamblea Nacional constituyente, 2008, art. 86) En la perspectiva que aquí se adapta según (Ferrajoli, 2000), son garantías jurisdiccionales:

Obligaciones a cargo de los órganos judiciales encargados de aplicar las sanciones o de declarar la anulación, ya se trate en el primer caso de actos ilícitos o en el segundo de actos inválidos que violan los derechos subjetivos y con ello, lo relativo a las garantías primarias. (p. 10)

Es decir, el juez es competente de conocer los hechos donde se originó el acto o la omisión de vulneración de derechos, es decir, tiene competencia cualquier juez de primera instancia que sea competente dentro de su jurisdicción, las garantías jurisdiccionales como acción extraordinaria de protección, acción por incumplimiento y acción de incumplimiento, será competencia de la Corte Constitucional y deberán ser interpuestas a este órgano. Las acciones de garantías jurisdiccionales pueden ser por cualquier persona, comunidad, pueblo, nacionalidad o colectivo, que se encuentre vulnerados o violentados sus derechos constitucionales (Vásquez-Zambrano, NarváezZurita, Borja-Pozo, \& Erazo-Álvarez, 2020).

En este mismo contexto, nos referiremos a los principios constitucionales, son normas jurídicas las cuales se refieren a los derechos y a la organización del Estado, los encontramos tanto en la Constitución, normas Internacionales, así como también en el sistema jurídico. Por lo tanto, los principios constitucionales tienen como función lograr en un nivel gran nivel una vida digna. "Los principios son mandatos de optimización o 
normas jurídicas y, como tales, deben ser aplicadas..." (Alexy, 2016).

La dignidad de la persona es un derecho y es aplicada sin distinción alguna, se puede indicar que es un derecho absoluto, la cual proteger y se reconoce en el Art, 11, nro. 7 de la CRE siendo el fin supremo de un Estado, la dignidad humana es el núcleo principal de nuestro ordenamiento jurídico, sirviendo como principio rector para la interpretación constitucional y para la evaluación de la adecuación constitucional de las normas que se expidan. Así tomando la filosofía kantiana de la dignidad y del ser humano no puede ser relativizada independientemente la persona es un delincuente o no. La dignidad es la condición mínima y la esencia que hace del ser como único e invaluable.

De igual forma, en nuestra carta magna se encuentra reconocido el principio de supremacía constitucional, este principio se divide como material y formal. La supremacía material indica que siempre prevalecerá lo que se encuentra consagrado en la CRE y su rigidez al momento de realizar una reforma las cuales deben de ser apegadas a nuestra carta magna; por otro parte, la supremacía formal se refiere a las normas, leyes que se encuentra de menor jerarquía que la Constitución las cuales deberán ser ajustadas a nuestra carta magna. Por esta razón la Corte Constitucional cumple un importante rol, ya que es la institución encargada de realizar un correcto control a la Constitución y observar que la aplicación sea de forma correcta, por último, su contexto debe ser desarrollado en base a la norma suprema que es la CRE como lo indica el principio de supremacía constitucional, de igual forma, existe el principio de legalidad, este principio permite que los contextos tanto en la Constitución o las normas de menor jerarquía, se desarrollen legislativamente.

Dentro de este marco, la Corte Constitucional realizó un pronunciamiento sobre las normas infra-constitucionales, indicando que la justicia ordinaria deberá cumplir y garantizar los derechos que se encuentren establecidos en la Constitución, manifestando que "los principios constitucionales forman un conjunto homogeneizado por el dato capital de su supremo valor normativo dentro del ordenamiento jurídico" (Canales, 2006, p. 146) En el artículo 426 de la CRE nos indica que los jueces, autoridades administrativas y servidores públicos, les corresponderá aplicar de forma directa las disposiciones 
normativas constitucionales y las que se encuentran establecidas en los instrumentos internacionales, de igual forma, se aplicará la norma más favorable, pero si un juez/a, o los sujetos procesales indique que la norma es inconstitucional o no se encuentra adecuada a la Constitución, el juez/a tiene la obligación de suspender el trámite del proceso y procederá a realizar una consulta a la Corte Constitucional; los jueces de la Corte deberán pronunciarse sobre la consulta realizada. Mediante ese mecanismo Estado puede garantizar a los ciudadanos la efectiva protección y aplicabilidad de los derechos fundamentales, impidiendo que exista algún tipo de violación, discriminación o vulneración.

\section{La reincidencia en materia penal con implicaciones sancionatorias}

A lo largo de la historia el hombre ha tratado de mejorar los comportamientos no aceptados por la sociedad, comportamientos de actos delictivos que ponen en riesgo la armonía y tranquilidad de un pueblo, es por ello, que han considerado que una de las soluciones para poder contralar estos actos es imponiéndoles castigos severos y si la persona vuelve a delinquir el castigo aumentaría, de esta manera se trata de mejorar las conductas no aceptadas por la sociedad y en la actualidad la mayoría de país aplican esta medida aumentado la pena a la persona que es reincidente en actos delictivos.

La reincidencia criminal se refiere a la repetición del cometimiento de actos delictivos la cual es sancionada drásticamente incrementando la pena a quien reincide en actos reprochables ante la sociedad y al Estado, sin embargo, la persona que reincide ha sido juzgado y condenado previamente por el cometimiento de otros delitos, en cierto modo, el Estado trata de controlar que las personas no vuelvan a cometer actos delictivos. (Bernabete-Ochoa, 2016).

Existe dos posturas a la reincidencia penal, por un lado se refiere a la teoría afirmativa de la reincidencia, en razón que mediante el derecho penal a la tipificación de esta circunstancia de agravación punitiva y por otro corresponde a las llamadas teorías abolicionistas de la reincidencia, en razón a que no solo critican a esta figura jurídica, sino que no aceptan su existencia y operatividad en el derecho penal (Martínez-Espinosa, 

2016).

Ahora bien, se puede indicar que la reincidencia en materia penal por un lado busca proteger a la sociedad en los altos índices delictivos, imponiendo un apena por encima del extremo máximo prevista por el tipo penal para satisfacer los fines sociales, pero se debe tener en cuenta que esta medida ha vulnerado la dignidad del ser humano y por otro lado inobserva los derechos y garantías constitucionales (Reyes-Cueva, ErazoÁlvarez, Borja-Pozo, \& Narváez-Zurita, 2020).

Con la aplicación de la reincidencia existe una vía de doble lesión o en otras palabras provoca dos daños, la primera inmediato (delito en particular) se refiere a la afectación de derechos fundamentales del procesado y la segunda mediato (violación al ordenamiento jurídico) refiriéndose a la vulneración de derechos y garantías constitucionales consideración que la aplicación de la reincidencia incumple la jerarquización de las normas, es por ello, que se consideraría que la reincidencia es injusto ya que para sancionar el segundo delito se considera el primer delito cometido.

Los tratadistas han dividido a la reincidencia en genérica y especial, la reincidencia genérica se refiere a la persona que por varias ocasiones comete actos delictivos, es decir, que los delitos que se cometan con posterioridad, pero no es el mismo elemento de tipicidad. Mientras que la reincidencia especial se refiere al mismo elemento de tipicidad, es decir, que el nuevo delito es igual al delito cometido anteriormente (Ossa, 2010).

Por lo tanto, la reincidencia es regulada por la legislación penal, pero no existe una explicación doctrinal el cual explique si el aumento de la pena por reincidencia es o no constitucional, el término reincidencia se describe como el cometimiento de por varias ocasiones un acto. Según el concepto admitido por el legislador, se trata de la repetición de la infracción cometida por una persona anteriormente condenada por un delito existiendo sentencia condenatoria. El problema social que existe cuando las personas retornan al cometimiento de actos delincuenciales y el derecho penal lo ha considerado como circunstancia para agravar la sanción penitenciaria (Martinez, 2011). 


\section{La declaración de inconstitucionalidad respecto de las sanciones}

Como se ha indicado, la CRE es la norma suprema de nuestro ordenamiento jurídico, siendo de directa e inmediata aplicación, así mismo, será inconstitucional cualquier acción u omisión de carácter regresivo que disminuya, menoscabe o anule injustificadamente el ejercicio de los derechos. Es importante indicar que en la realidad no se cumple lo que la CRE indica, existiendo inconsistencias en las normas infraconstitucionales ya que no se encuentran apegadas a nuestra carta magna, en nuestro ordenamiento jurídico se considera como agravante el ser reincidente en actos delictivos de una persona "Si la persona reincide se le impondrá la pena máxima prevista en el tipo penal incrementada en un tercio" Asamblea Nacional , 2014, (art. 57).

Es importante analizar si el Art. 57 del COIP siendo una norma de menor jerarquía que la CRE, violenta o no derecho o garantía reconocido en la Constitución, por lo que a continuación se realizará un análisis entre los derechos, garantías y principios constitucionales que pueden ser afectados o se encuentran afectados con la aplicación de la reincidencia en materia penal.

Según se encuentra establecido en el art. 11 de la CRE "Nadie podrá ser discriminado por razones de etnia, lugar de nacimiento, edad, sexo, pasado judicial ni por cualquier otra distinción" Asamblea Nacional Constituyente, (2008). Este principio de no discriminación por el pasado judicial es uno de los derechos primordiales de las personas y de igual forma es uno de los pilares que cualquier sistema democrático lo reconoce. Existiendo también el reconocimiento de convenios y tratados internacionales como: Declaración Universal, Pacto Internacional de Derechos Civiles y Políticos, la Convención Americana, la Convención Europea de Derechos del Hombre y Protocolos (ParedesAldas, 2017). Sin embargo, al momento que una persona reincide en actos delictivos para establecer su responsabilidad penal se considera el pasado judicial de la persona, de este modo, la reincidencia pretende castigar a la persona que es reincidente en infracciones cometidas con los mismos elementos de tipicidad de dolo y culpas, el juzgador observar el pasado judicial de la persona para establecer una sancionar, sin que se analice que la persona procesada fue sentenciada por el delito antes cometido e 
inclusive en varias ocasiones el daño causado a sido reparado, de este modo, se ha criminalizado por su pasado judicial y en consecuencia se violenta la norma constitucional, al no recibir la igualdad de trato siendo discriminado por su pasado judicial (Encarnación-Díaz, Erazo-Álvarez, Ormaza-Ávila, \& Narváez-Zurita, 2020).

La CRE se encuentra consagra en su Art 66 “...el derecho a la igualdad formal, igualdad material y no discriminación". (Asamblea Nacional Constituyente, 2008), se entiende por igualdad formal, la igualdad que tenemos las personas ante la ley, es decir, una igualdad en cuanto a la configuración y aplicación de normativa jurídica, mientras que la igualdad material se refiere a las particularidades de los sujetos, grupos o colectivos, quienes deben ser tratados de manera igualitaria si se encuentran dentro de circunstancias fácticas similares, prohibiéndose todo acto discriminatorio (Corte Constitucional del Ecuador, 2018).

El derecho a la igualdad es el derecho que todos los ciudadanos tenemos a ser tratados de igual forma ante la sociedad y ante la ley. Pero el derecho a la igualdad y no discriminación también se encuentra reconocido en tratados y convenios internacionales como: La Declaración de los Derechos Humanos Art. 7, Convención Americana Sobre Derechos Humanos Art. 24. Dentro de este marco, se consagra los principios constitucionales los cuales son aplicados a la norma jurídica penal, siendo el principio del non bis in ídem, que se encuentra conectado al derecho de la seguridad jurídica y derecho a la cosa juzgada, materializándose en la seguridad y la eficacia jurídica.

El principio de non bis in ídem es la seguridad jurídica que el Estado otorga a los ciudadanos impidiendo que se sancione por varias ocasiones un mismo delito protege a hechos ya sancionados para que no vuelvan a ser sancionados por el mismo delito cometido. En definitiva el principio del non bis in ídem prohíbe que exista una doble sanción por los hechos cometidos por una persona, el mimo principio lo podemos encontrar en la Constitución del Ecuador "Nadie podrá ser juzgado más de una vez por la misma causa y materia" (Caso Loayza Tamayo Vs. Perú (CIDH), 1997); (Andrade, 2017).

Otro principio constitucional que se encuentra afectado frente a la aplicación de la 
reincidencia en materia penal, es el principio de proporcionalidad; este principio protege a las personas procesadas, adecuando la gravedad de su delito con su sanción. El principio de proporcionalidad deriva consecuencialmente del carácter retributivo de la pena, según se encuentra señalado en la CRE, Asamblea Nacional Constituyente, (2008) "La ley establecerá la debida proporcionalidad entre las infracciones y las sanciones penales, administrativas o de otra naturaleza". (Art. 76 n. 6).

De igual forma Asamblea Nacional Constituyente, (2014) "las sanciones disciplinarias que se impongan a la persona privada de libertad, deberán ser proporcionales a las faltas cometidas. No se podrán imponer medidas sancionadoras indeterminadas ni que contravengan los derechos humanos" (p.12, n.16). Al momento que se realiza un incremento a la sanción de la responsabilidad cometida, el procesado no estaría recibiendo una sanción adecuada, ya que para establecer una sanción se revisa su pasado judicial.

Con el análisis realizado se puede determinar, que, con la aplicación de la reincidencia, las garantías y principios constitucionales no cumplen su funcionamiento efectivamente ya que están siendo vulnerados e inobservados. El hecho de agravar la sanción penitenciaria considerando el pasado judicial del procesado se puede considerar que existe discriminación por parte del Estado a la persona procesada ya que no recibe un igual trato y una sanción justa, impídenos que este grupo de personas se reinserten a la sociedad. El derecho penal de un Estado no debe ser objeto de sanción el pasado judicial de una persona para agravar la pena.

Es por ello, que la reincidencia en matrería penal no debería ser aplicada ya que se consideraría que la reincidencia tiene mayor peso a los principios y garantías constitucionales, irrespeta la jerarquización de las normas, inobserva el principio de supremacía constitucional y el derecho a la seguridad jurídica entre otros principios y garantías como lo hemos analizado con anterioridad.

Los efectos de la reincidencia en el derecho penal también es un atentado para la dignidad de la persona. Porque en este caso el ser humano se convierte en un mero 
objeto y deja de ser un sujeto de derecho; transformándose en un medio para lograr un fin. Tomar como referencia la personalidad o la vida del ser humano y poner penas que sobrepasen la culpabilidad del hecho para satisfacer los fines sociales es indigno para el ser. Es necesario que exista un estudio minucioso sobre las causales para que las personas vuelvan a reincidir en delitos y establecer los delitos que con mayor frecuencia se cometen en el Ecuador, para que el Estado mediante la ayuda de la sociedad pueda frenar los índices delictivo y que las personas recaigan en el cometimiento de actos delictivos, ya que se ha determinado que una condena no es una solución para cambiar la realidad de país si no existe verdadera rehabilitación y ayuda a las personas antisociales, de manera que se evite la violación de las garantías y principios constitucionales, que exista similitud con la norma suprema y los Instrumentos Internacionales, donde predomine la semejanza de las normas de menor grada a las normas supremas, que sea viable a la hora de ser puesta en práctica.

\section{MÉTODO}

El método utilizado fue cualitativo - cuantitativo, de carácter no experimental por lo que se realizó el estudio pertinente de las variables, la presente investigación se realizó el estudio de las variables en el contexto actual de los hechos, sin manipularlas, para su posterior análisis, síntesis y conclusiones. El enfoque es mixto (cualitativo - cuantitativo) el cual se basa en analizar las situaciones, desde lo más detallado hasta lo general y de forma inversa. Histórico-Lógico, en función a la bibliografía consultada de acuerdo a su cronología (Hernandez-Sampleri, Frenandéz-Collado, \& Baptista-Lucio, 2010).

Así mismo, se utilizó el método analítico-sintético con el que se descompone un todo en sus partes, que permite estudiar a detalle cada una de ellas, y luego, al integrarlas conocer su interrelación (Behar-Rivero, 2016). La aplicación de todos estos métodos permitió analizar teorías, doctrina, leyes, jurisprudencia extranjera, bibliografía, como parte de la población de estudio, generándose mediante el análisis documental jurídico, la construcción de aportes reflexivos teóricos en el campo del derecho constitucional. 


\section{Universo de estudio y tratamiento muestral}

Dentro del universo del estudio se utilizó el muestreo no probabilístico y aleatorio, en lo que se consideró los casos accesibles de la investigación, en esta ocasión se utilizó el criterio de abogados en libre ejercicio y funcionarios del Consejo de la Judicatura dando un total de 27 personas que fueron encuestados las cuales aportaron a la investigación dando su punto de vista sobre la reincidencia en materia penal que es aplicada en nuestro país.

\section{Tratamiento estadístico de la información}

Se obtuvo los datos mediante encuestas, realizando un formulario a través de la página WEB (https://docs.google.com/forms), una vez obtenido los resultados fueron procesados y procediendo a tabular los resultados más significativos en el programa Microsoft Excel versión 2019 (Lema-Guiracocha, Erazo-Álvarez, \& Narváez-Zurita, 2019).

\section{RESULTADOS}

A continuación, se presenta la tabla 1 y figura 1, el cual representa los resultados obtenidos, clasificados según las variables definidas en el instrumento de la investigación aplicando: Los resultados de encuestas aplicadas a abogados en libre ejercicio y funcionarios del Consejo de la Judicatura, quienes cuentan con un amplio conocimiento constitucional y penal. 
Iustitia Socialis. Revista Arbitrada de Ciencias Jurídicas.

Año V. Vol. V. $\mathrm{N}^{\circ}$ 9. Julio - Diciembre 2020

Hecho el depósito de Ley: FA2016000064

ISSN: $2542-3371$

FUNDACIÓN KOINONIA (F.K). Santa Ana de Coro, Venezuela

Ivanova María Ramírez-Tenepaguay; Juan Carlos Erazo-Álvarez; Cecilia Ivonne Narváez-Zurita; Enrique Eugenio Pozo-Cabrera

\section{Tabla 1}

Resultados de la encueta por variables

\begin{tabular}{ccc}
$\begin{array}{c}\text { Encuesta } \\
\text { Variables }\end{array}$ & \multicolumn{2}{c}{ Si Resultados \% } \\
\hline Derogar & $81.48 \%$ & No \\
Principios & $74.07 \%$ & $18.52 \%$ \\
Pasado Judicial & $22.22 \%$ & $25.93 \%$ \\
Discriminación & $29.63 \%$ & $77,78 \%$ \\
Rehabilitación & $7.41 \%$ & $70.37 \%$ \\
\hline
\end{tabular}

Fuente: Investigación de campo

\section{Resultados}

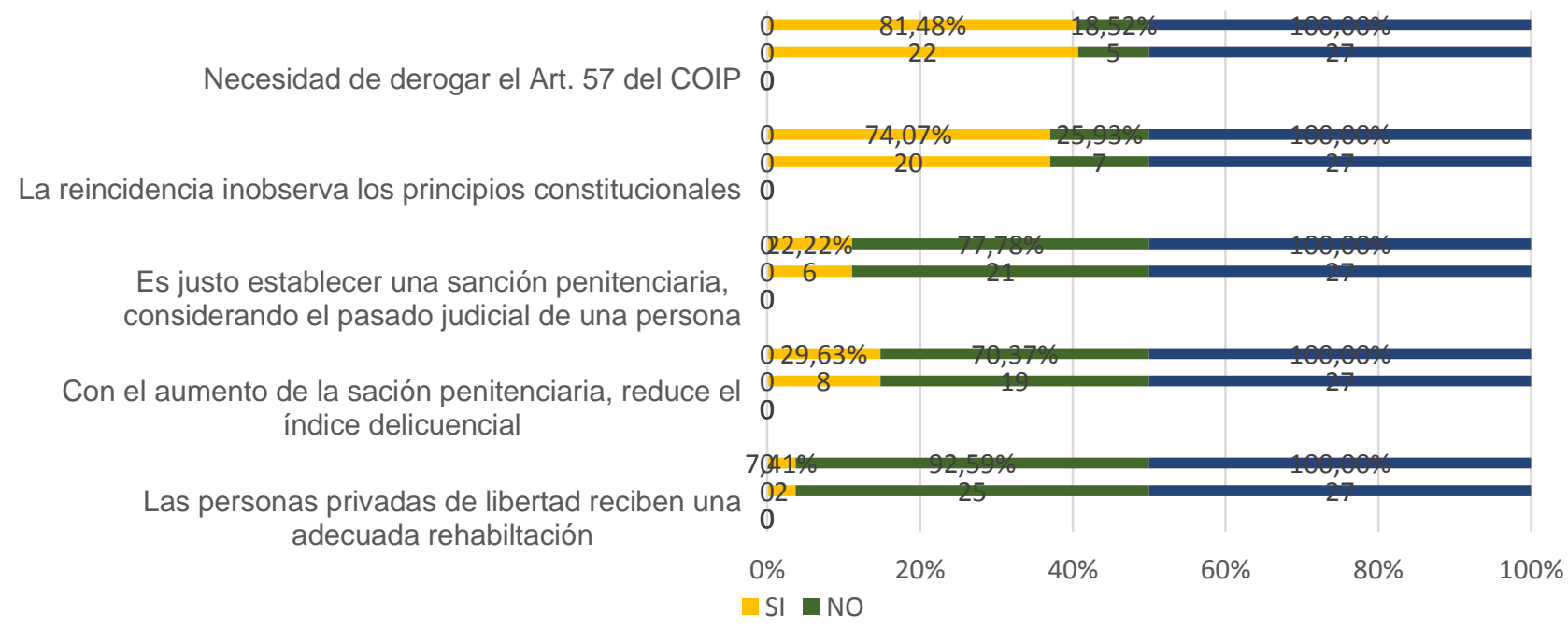

Figura 1. Representación gráfica de los resultados. Fuente: Investigación de campo. 
Con los resultados obtenidos mediante las encuestas realizadas, se ha podido determinar que la aplicación del Art. 57 del COIP, vulnera los derechos de los procesados, como también inobserva los principios y garantías constitucionales, así mismo; los encuestados indicaron que el aumento de la pena, no es la medida adecuada para poder controlar los índices delictivos de un país ya que en los centros de rehabilitación las personas detenidas no cuentan con una verdadera rehabilitación y al no contar con una rehabilitación adecuada se vuelve imposible que las personas privadas de la libertad se reintegren de forma efectiva a la sociedad, en otras palabras el internamiento en la cárcel sería un factor criminógeno, no de recuperación social del reo.

De igual forma, indicaron que el aumento de la condena por reincidencia en actos delictivos claramente vulneran los principios constitucionales como el principio de proporcionalidad, y el principio non bis in ídem, de igual forma vulnera el derecho a la seguridad jurídica, según Carbonell, 2008, (p. 44) “...los principios se aplican mediante la ponderación", refiriéndose que siempre se deberá realizar una balance entre principios para de esa forma terminar el principios más favorable para al procesado, y por ende, la aplicación de estos principios son de aplicación directa e inmediata, de manera que no requiere de la normatividad jurídica secundaria para su pre-seguridad, siendo su ámbito de acción ilimitada en razón de la materia ya que es aplicable a todo tipo de resoluciones judiciales o administrativas.

Se puede también indicar que la reincidencia en materia penal es un atentado para la dignidad de la persona, en este caso la persona se convierte en un mero objeto y deja de ser un sujeto de derecho; convirtiéndose en un medio para satisfacer los fines sociales, considerar el pasado judicial para establecer una sanción penitenciaria que sobrepase la culpabilidad del hecho, no solo es acto de discriminación, sino es indigno para el ser. 


\section{PROPUESTA}

\section{Objeto}

El presente documento tiene por objeto proponer una reforma a la reincidencia en materia penal como circunstancia de agravante de la pena, según se encuentra estipulado en el Art. 57 del COIP, de igual forma, dar a conocimiento a la Asamblea Nacional para su primer debate.

\section{Exposición de motivos}

Los altos índices delictivos es un problema social que vive el país, el problema radica por la falta de oportunidades para poder obtener educación, trabajo entre otros factores, sin que exista ayuda por parte del Estado ante este problema que a la mayoría de ciudadanos afecta, por lo contrario el Estado ha tomado como medida endurecer la sanción penitenciaria a las personas que reincidan en actos delictivo, pero esta medida no ha sido una solución para resolver el problema social, ni disminuir el índice delincuencia.

Se debe indicar que el Estado mediante la institución penal vulnera los derechos fundamentales de los procesados, mediante la aplicación de la reincidencia en materia penal trasgrediendo garantías y principios que se encuentran consagrados en la CRE, de igual forma se indica que la reincidencia no cumple los fines de la pena como lo indica el Art. 52 del COIP.

\section{Elementos constitucionales}

El presente proyecto de ley reconoce el ordenamiento jurídico y tiene como base adecuar la norma infra-constitucionales a la norma suprema, siendo el caso, que la aplicación de la reincidencia debería ser apegada a nuestra carta magna. Evitando que se siga vulnerando los derechos constitucionales de los procesados, estos derechos son reconocidos en la CRE siendo de inmediato cumplimiento y aplicación, según se encuentra establecido en la Constitución de la República del Ecuador, Art. 11, numerales.

3.- Los derechos y garantías establecidos en la Constitución y en los 
instrumentos internacionales de derechos humanos serán de directa e inmediata aplicación [...]

4.- Ninguna norma jurídica podrá restringir el contenido de los derechos ni de las garantías constitucionales.

7.- El reconocimiento de los derechos y garantías establecidos en la Constitución y en los instrumentos internacionales de derechos humanos, no excluirá los demás derechos derivados de la dignidad de las personas,

En el mismo cuerpo legal en su Art 76, numeral

\section{6.- La ley establecerá la debida proporcionalidad entre las infracciones y las sanciones penales, administrativas o de otra naturaleza.}

En función a las conclusiones arribadas, se propone sustituir el inciso 3 artículo 57;

Eliminar el numeral 9 del Art. 631; Eliminar en el Art. 725 la palabra "reincidencia" del Código Orgánico Integral Penal.

\section{Tabla 2}

Sustitución de artículos propuestos

\section{Actual}

\section{Reformado}

Art. 57.- Reincidencia.- $\mathrm{Si}$ la persona reincide se le impondrá la pena máxima prevista en el tipo penal incrementada en un tercio.

Artículo 631. Condiciones. - La persona sentenciada durante el período que dure la suspensión condicional de la pena cumplirá con las siguientes condiciones

9.- No ser reincidente
Art. 57.- Reincidencia.- Si la persona reincide se le se aplicará la pena establecidas en el mismo cuerpo legal, así mismo deberá asistir a programas que preste el centro de rehabilitación cumpliendo las horas que el juez dictamine.

Derogado el numeral 9 del Artículo 631

Artículo 725. Sanciones.- Se impondrán las Artículo 725.- Sanciones.- Se impondrán 
siguientes sanciones dependiendo de la gravedad y reincidencia, las que deben justificarse en virtud de la proporcionalidad y características de la falta cometida. las siguientes sanciones dependiendo de la gravedad, las que deben justificarse en virtud de la proporcionalidad y características de la falta cometida.

Fuente: Código Orgánico Integral Penal

\section{DISCUSIÓN}

A través de la investigación realizada sobre el problema de la reincidencia y su conceptualización, se logró determinar, que la aplicación de la reincidencia como agravante sancionatorio, según se encuentra manifiesta en el Art. 57 del COIP, inobserva derechos, garantías y principios que se encuentran reconocidos en la CRE e Instrumentos Internacionales de ser humano, de este modo no se limitaría la potestad punitiva. Así mismo, se realizó diferentes enfoques de estudio donde se pudo comprender que la reincidencia en materia penal, concurre una serie de factores internos y externos, de igual forma, no se ha podido identificar jurídicamente las razones del por qué el Estado mediante sus órganos competentes toma como agravante hechos que en su debido tiempo obtuvo su castigo con la justicia y la sociedad.

En nuestro país se reconoce a la reincidencia por delitos cometidos con anterioridad de igual semejanza de tipicidad, dolo y culpa, incrementando la sanción penitenciaria con el fin de disminuir los índices delincuenciales, pero esta medida no ha sido una solución para resolver el problema social que existe en nuestro país, los operadores de justicia deberían realizar un estudio del porque la persona recae en el cometimiento de un nuevo delito, ya que existe varios factores para que este problema social se realice, siendo un factor la falta de empleo y más aún cuando las persona tiene antecedentes penales se le niega la oportunidad de un empleo, así mismo, otro factor seria la no adecuada rehabilitación a los reos en los centros penitenciarios, es de conocimiento público que en los centros de rehabilitación las personas privadas de libertad se perfeccionan en actos delictivo, sin que el Estado haga algo ante esta situación. 
Ecuador siendo un Estado garantista de los derechos de las personas, reconoce el derecho a la vida y a la integridad física y moral, sin que, en ningún caso, puedan ser sometidos a tortura ni a penas o tratos inhumanos o degradantes, de igual forma, garantizado una adecuada rehabilitación y reinserción social como finalidad de la pena. Es necesario que las autoridades estatales, administrativas, jurisdiccionales y legisladores, realicen un estudio interdisciplinario sobre el tema el cual asegure el cumplimento efectivo de los derechos y garantías constitucionales. Finalmente, es necesario la creación de políticas y programas de rehabilitación, para posterior a ello exista una adecuada reinserción social, con el fin de generar oportunidades efectivas de superación a quienes cumplieron una condena y han recuperado su libertad. Programas en los que se involucre a la sociedad que necesariamente debe despojarse de estereotipos.

\section{FINANCIAMIENTO}

No monetario.

\section{AGRADECIMIENTO}

A los abogados en libre ejercicio y funcionarios del Consejo de la Judicatura que apoyaron la investigación.

\section{REFERENCIAS CONSULTADAS}

Alexy, R. (17 de 07 de 2016). Teoría de Los derechos fundamentales [Theory of the fundamental rights]; recuperado de: https://n9.cl/a03v. UNAM, 241-245. Obtenido de Cuestiones Constitucionales.

Andrade, M. Y. (2017). Principio de non bis in idem [Non bis in idem principle]; recuperado de; https://n9.cl/sjzk. Derecho Ecuador.

Asamblea Nacional. (10 de febrero de 2014). Código Orgánico Integral Penal [Organic Comprehensive Criminal Code]. Penas y medidad de seguridad. Quito, Pichincha, Ecuador: Registro Oficial 180. 
Asamblea Nacional Constituyente. (05 de 06 de 1998). Constitución Política de la República del Ecuador [Political Costitucion of the Republic of Ecuador]. Riobamba, Chimborazo, Ecuador: Registro Oficial 1.

Asamblea Nacional Constituyente. (20 de 10 de 2008). Constitución de la República del Ecuador [Constitution of the Republic of Ecuador]. Montecristi, Manta, Ecuador: Registro Oficial.

Asamblea Nacional Constituyente. (2008). Constitución de la República del Ecuador [Constitution of the Republic of Ecuador]. Garantias constitucionales. Montecristi, Manta, Ecuador: Registro Oficial 449.

Behar-Rivero. (2016). Metodoligía de la Investigación [Research Methodology]; recuperado de: https://n9.cl/x28m. A. Rubeira, 1-94.

Bernabete-Ochoa, F. (2016). La reincidencia como circunstancia agravante de la pena [Recidivism as an aggravating circumstance of the sentence]; recuperado de. https://n9.cl/rOp9. Sergio Alboleda, 184.

Carbonell, M. (2008). El principio de proporcionalidad y la interpretación constitucional [The principle of proportionality and the constitutional interpretation]; recuperado de: https://n9.cl//6vf. Ministerio de justicia y derechos humano, 1-349.

Caso Loayza Tamayo Vs. Perú (CIDH) [Case of Loayza Tamayo v. Peru]; recuperado de: https://n9.cl/sky4, Serie C No. 25, Serie C No. 33, Serie C No. 42, Serie C No. 47, Serie C No. 53, Serie C No. 60 (Hernán Salgado Pesantes; Antônio Cançado Trindade; Héctor Fix Zamudio; Alejandro Montiel Argüello; Máximo Pacheco Gómez; Oliver Jackman; Alirio Abreu Burelli 17 de 09 de 1997). Obtenido de http://www.corteidh.or.cr/docs/casos/articulos/seriec_33_esp.pdf

Chávez, J. (2016). La justicia indígena: la reincidencia en los delitos contra la propiedad [Indigenous justice: recidivism in property crimes]; recuperado de: https://n9.cl/8ljo. Universidad Andina Simón Bolívar, Sede Ecuador, 13.

Corte Constitucional del Ecuador. (2018). Derecho a la igualdad y a la no dicriminación [Right to equality and non-discrimination]; recuperado de: https://n9.cl/o7s3. Litígios complejos en las Américas, 1-6.

Encarnación-Díaz, A. B., Erazo-Álvarez, J. C., Ormaza-Ávila, D. A., \& Narváez-Zurita, C. I. (2020). La defensa técnica del procesado: Derecho a la defensa y debido proceso [The technical defense of the accused: Right to defense and due process]. Iustitia Socialis, 511-537. doi:http://dx.doi.org/10.35381/racji.v5i1.628 
Ivanova María Ramírez-Tenepaguay; Juan Carlos Erazo-Álvarez; Cecilia Ivonne Narváez-Zurita; Enrique Eugenio Pozo-Cabrera

Ferrajoli, L. (2000). Garantías constitucionales [Constitutional guarantees]; recuperado de: https://n9.cl/96fc. Revista Argentina de Derechos, 10.

Hernandez-Sampleri, Frenandéz-Collado, \& Baptista-Lucio. (2010). Metodoligían de la investigación [Research methodology]; recuperado de: https://n9.cl/px0c. Free libros, 1-611.

Lema-Guiracocha, P. E., Erazo-Álvarez, J. C., \& Narváez-Zurita, C. I. (2019). El talento humano, factor clave para la gestión organizacional en Instituciones de intermediación financiera. [Human talent, a key factor for organizational management in financial intermediation institutions]. Revista Arbitrada Interdisciplinaria Koinonía, 360. doi:http://dx.doi.org/10.35381/r.k.v4i1.461

Martinez, A. (2011). La Reincidencia [Recidivism]; recuperado de: https://n9.cl/x3mf. Universidad de Murcia, 598-625. doi:http://dx.doi.org/10.22201/fder.24488933e.2018.272-2.67582

Martínez-Espinosa, P.-C. P.-C. (2016). La reincidencia en el derecho penal colombiano [Recidivism in Colombian criminal law]. 1-664. doi:http://dx.doi.org/10.15425/redepub.37.2016.05

Montaña, J., \& Porras, A. (2011). Apuntes de derecho procesal constitucional [Notes on constitutional procedural law]; recuperado de https://n9.cl/2xl9. Tribunal contencioso electoral.

Ossa, M. F. (2010). Aproximaciones Conceptuales a la reincidencia penitenciaria [Conceptual approaches to prison recidivism]; recuperado de: https://n9.cl/85bp. Dialnet plus, 133.

Paredes-Aldas, H.-L. (2017). El ingreso al sector público ecuatoriano y el principio de no discriminaciónpor el pasado judicial [Entering the Ecuadorian public sector and the principle of non-discrimination because of the judicial past], Recuperado de: https://n9.cl/g6sc. Universidad Técina de Ambaro, 1-95.

Reyes-Cueva, M. d., Erazo-Álvarez, J. C., Borja-Pozo, C. A., \& Narváez-Zurita, C. I. (2020). Mínima intervención penal en el juzgamiento contra delitos menores: Tutela judicial efectiva y reparación integral [Mínima intervención penal en el juzgamiento contra delitos menores: Tutela judicial efectiva y reparación integral]. Iustitia Socialis, 295-311. doi:http://dx.doi.org/10.35381/racji.v5i1.613 
Rojas-Valdivieso, M. C., Erazo-Álvarez, J. C., Pozo-Cabrera, E. E., \& Narváez-Zurita, C. I. (2020). Prueba en Garantías Jurisdiccionales. Falta de regulación y afección al derecho a la defensa y libertad probatoria en el Ecuador [Evidence on Jurisdictional Guarantees. Lack of regulation and infringement of the right to defense and evidentiary freedom]. lustitia 44. doi:http://dx.doi.org/10.35381/racji.v5i8.560

Vásquez-Zambrano, T. P., Narváez-Zurita, C. I., Borja-Pozo, C. A., \& Erazo-Álvarez, J. C. (2020). Habeas corpus como mecanismo de garantía de derechos de las personas privadas de libertad [Habeas corpus as a mechanism to guarantee the rights of persons deprived of liberty]. Iustitia Socilais, 140-158. doi:http://dx.doi.org/10.35381/racji.v5i1.606 